\title{
Associação de sulfentrazone e glyphosate para o controle de plantas daninhas na cultura da soja $\mathbf{R R}^{\circledR}$
}

\author{
Association of sulfentrazone and glyphosate for weed control in $\mathrm{RR}^{\circledR}$ soybean
}

\author{
Jethro Barros Osipe ${ }^{1}$, Emerson da Silva Teixeira ${ }^{2}$, Robinson Osipe ${ }^{3}$, Maria Aparecida da \\ Fonseca Sorace, ${ }^{3}$ Conceição Aparecida Cossa ${ }^{3}$, Antonio Mendes de Oliveira Neto ${ }^{1}$
}

\begin{abstract}
Resumo - A utilização de herbicidas com atividade residual, na operação de manejo, tem se tornado uma prática comum a fim de diminuir a competição inicial exercida pelas plantas daninhas. O presente trabalho tem como objetivo avaliar a seletividade e a eficiência da associação de glyphosate+sulfentrazone, na operação de manejo em pré-plantio, complementada com glyphosate em pós-emergência. Para isso, instalou-se um experimento na cidade de Bandeirantes, PR, em um Latossolo Roxo Eutrófico. O delineamento experimental utilizado foi em blocos ao acaso, em esquema de parcelas subdivididas, com 11 tratamentos e 04 repetições. As principais plantas daninhas presentes na área experimental (Bidens pilosa e Commelina benghalensis) encontravam-se em pleno desenvolvimento vegetativo no momento da aplicação de manejo. Foram avaliados, neste período, a fitointoxicação dos tratamentos à cultura da soja, a densidade de plantas daninhas e o rendimento de grãos da cultura. Os resultados mostraram que o herbicida sulfentrazone reduziu significativamente a densidade de Bidens pilosa e Commelina benghalensis, o que garantiu um aumento de produtividade de até $22,49 \%$. Além disso, a cultura da soja não apresentou sintomas de fitointoxicação pela utilização dos herbicidas.
\end{abstract}

Palavras-chave: Competição inicial, seletividade, produtividade, soja transgênica

\begin{abstract}
The use of herbicides with residual activity in weed management has become a common practice in order to reduce weed initial competition. This study aims to evaluate the selectivity and efficiency of the sulfentrazone + glyphosate association at pre-planting management, supplemented with postemergence glyphosate. To reach such intent, an experiment was conducted in Bandeirantes - Pr, on a Eutrophic latosol. The experimental design was randomized blocks in split plot scheme with 11 treatments and 04 replicates. The main weeds in the experimental area (Bidens pilosa, Commelina benghalensis) were in full vegetative growth at the time of application management. During this period, injury caused by treatment to soybean crop, weed density, and grain yield were evaluated. The results showed that sulfentrazone significantly reduced the density of Bidens pilosa and Commelina benghalensis, which ensured an increase in yield of up to $22.49 \%$. In addition, no symptoms of injury were observed by the use of herbicides.
\end{abstract}

Key-words: Initial competition, selectivity, productivity, transgenic soybean

\footnotetext{
${ }^{1}$ Mestrando em Agronomia pela Universidade Estadual de Maringá, Maringá, PR, <jethrosipe@ @otmail.com>

${ }^{2}$ Mestrando em Agronomia pela Universidade Estadual de Londrina

${ }^{3}$ Professor Adjunto pela Universidade Estadual do Norte do Paraná - Campus Luiz Meneghel
} 


\section{Introdução}

A soja é uma espécie exótica à flora brasileira, originária de regiões de clima temperado, apresentando assimilação do carbono pelo ciclo $\mathrm{C} 3$, portanto, é uma planta menos eficiente fotossinteticamente quando comparada com plantas do tipo C4 (Casaroli et al., 2007). Ela pode sofrer com a interferência imposta pelas plantas daninhas, quando estas convivem ao mesmo tempo em um ambiente com recursos limitados ao crescimento. $\mathrm{O}$ pior momento em que pode ocorrer tal interferência é no chamado período crítico de prevenção à interferência. Para Pitelli (1987), este deve ser o período em que as capinas ou a atividade residual dos herbicidas atuam sobre as plantas daninhas. Isso porque a convivência das plantas daninhas com a cultura ocasiona perdas irreversíveis, tanto qualitativas como quantitativas.

Visando o manejo adequado e a manutenção da cultura livre de plantas daninhas nesta fase, recomendava-se o controle entre 15 e 40 dias após a emergência (Pitelli, 1985). No entanto, para Nepomuceno et al. (2007), o período crítico de prevenção de interferência está compreendido dos 33 aos 66 dias após a emergência da cultura.

$\mathrm{O}$ intervalo de tempo em que as plantas daninhas podem ter convivência com as culturas anuais, sem haver danos à produtividade, define-se como período anterior à interferência (PAI). Em termos de manejo de plantas daninhas, esse período torna-se o de maior importância do ciclo cultural, pois a partir dele a produtividade é significativamente afetada (Meschede et al., 2004).

Com as altas infestações de plantas daninhas, que ocorrem em algumas regiões do Brasil, os valores do PAI são baixos e o controle deve ser realizado numa fase bastante precoce do ciclo da cultura. Constantin et al. (2007) estabeleceram um PAI de 10 dias para a cultura da soja cv. Coodetec 202.
Segundo Carvalho et al. (2003), uma das alternativas para reduzir as reinfestações consideradas precoces é a utilização de herbicidas com atividade residual no processo de manejo ou dessecação em pré-plantio. Para ampliar o espectro de controle, têm-se lançado mão da utilização de associações. Na maioria das culturas, essa prática é comum e pode, segundo Damalas \& Eleftherohorinos (2001), aumentar o espectro de espécies controladas, além do período de controle destas (Vangessel et al., 2000).

Recentemente, com a introdução da soja tolerante ao glyphosate (Roundup Ready ${ }^{\circledR}$ ), o PAI passa a ter grande importância prática, pois a aplicação em pós-emergência pode ser efetuada no momento desejado, independente do estádio de desenvolvimento da cultura (Silva et al., 2009). No manejo convencional, grande parte dos produtos disponíveis no mercado não era eficiente no controle das invasoras, uma vez que a aplicação ocorria no final do PAI, quando a maioria das plantas daninhas já se encontrava em estádios de desenvolvimento mais avançado, dificultando o controle (Rodrigues \& Almeida, 2005).

O presente trabalho tem como objetivo avaliar a seletividade e a eficiência da associação de glyphosate+sulfentrazone, na operação de manejo em pré-plantio, complementada com glyphosate em pósemergência.

\section{Material e métodos}

No ano agrícola 2006/2007, foi realizado um experimento com a cultura da soja $\mathrm{RR}^{\circledR}$ no município de Bandeirantes, PR, em um Latossolo Vermelho Escuro Eutrófico.

Foi empregado delineamento experimental de blocos ao acaso, em esquema de parcelas subdivididas, com quatro repetições, e as parcelas com dimensões de $3 \mathrm{x}$ $15 \mathrm{~m}\left(45 \mathrm{~m}^{2}\right)$. Na instalação do experimento no 
campo, as parcelas foram divididas em 03 subparcelas, sendo uma central, representada pelos tratamentos com herbicidas aplicados em pós-emergência da cultura da soja $\mathrm{RR}^{\circledR}$, em diferentes épocas, (tratamentos principais) e duas outras subparcelas adjacentes, representadas pelos tratamentos com glyphosate aplicado em pós-emergência em um único momento (testemunhas).

Cada subparcela que recebeu o herbicida ficou com 02 outras adjacentes sem herbicidas, as quais foram denominadas testemunhas duplas. A técnica de testemunhas duplas foi descrita anteriormente por Fagliari et al. (2001), sendo inicialmente proposta para a avaliação da seletividade de herbicidas em cana-de-açúcar. Mais recentemente, foi utilizada também no estudo da seletividade de herbicidas na cultura da soja (Meschede et al., 2004; Jaremtchuk et al., 2008). Esse tipo de experimento confere maior controle sobre a variabilidade do meio, especialmente quando se utiliza o tradicional delineamento em blocos casualizados, com uma única testemunha por bloco (Meschede et al., 2004).

Em toda área experimental, a aplicação de manejo foi efetuada no dia 15/11/06 (28 dias antes da semeadura - DAS) com o herbicida glyphosate a $2880 \mathrm{~g} \mathrm{ha}^{-1}$. Nas testemunhas duplas, foi realizada aplicação pré-plantio no dia $11 / 12 / 06$, com o herbicida glyphosate a $1080 \mathrm{~g} \mathrm{ha}^{-1}$. Nos "tratamentos principais", também foi realizada aplicação pré-plantio no dia 11/12/06. As descrições dos tratamentos bem como as doses utilizadas estão apresentadas na Tabela 1. As condições climáticas durante o período do experimento se encontram na Figura 1.

A semeadura da cultura da soja foi efetuada no dia 13/12/06, no espaçamento de $0,45 \mathrm{~m}$, utilizando o cultivar CD $214 \mathrm{RR}^{\circledR}$ com 16 sementes por metro linear.

Após a emergência da cultura da soja $\mathrm{RR}$, foram realizadas aplicações em diferentes épocas de glyphosate a $980 \mathrm{~g} \mathrm{ha}^{-1}$, conforme
Tabela 1. As condições climáticas durante as aplicações foram: temperatura de 22 a $25{ }^{\circ} \mathrm{C}$, umidade relativa do ar entre 65 e $80 \%$ e ventos fracos de até $5 \mathrm{~km} \mathrm{~h}^{-1}$. Nas testemunhas duplas, foi efetuada uma única aplicação de glyphosate a $980 \mathrm{~g} \mathrm{ha}^{-1}$, aos 25 dias após a emergência da cultura, com condições climáticas semelhantes à citada acima.

As plantas daninhas predominantes na área experimental foram Bidens pilosa (picãopreto) e Commelina benghalensis (trapoeraba). Destaca-se que, na área experimental, as plantas daninhas se encontravam em pleno desenvolvimento vegetativo no momento da aplicação do manejo.

Aos 14 dias após a emergência da cultura da soja (DAE), foi efetuada a contagem das plantas daninhas nas 03 entrelinhas centrais das parcelas e subparcelas, com o objetivo de avaliar a atividade residual dos tratamentos, desprezando-se $1,0 \mathrm{~m}$ nas extremidades, e transformando-se posteriormente para obter a densidade (plantas $\mathrm{m}^{-2}$ ). Aos 15 e 30 DAE, avaliou-se a seletividade dos herbicidas aplicados, segundo escala EWCR. No dia 14/04/07, foi realizada a colheita manual, onde se cortou as 03 linhas centrais de cada parcela, desprezando-se $01 \mathrm{~m}$ nas extremidades, com posterior trilhagem e quantificação para obtenção da produtividade $\left(\mathrm{kg} \mathrm{ha}^{-1}\right)$.

Os dados oriundos da contagem das plantas daninhas e de produtividade foram submetidos à análise de variância pelo teste $\mathrm{F}$ e, para verificar diferença entre médias, utilizou-se o teste de Tukey em nível de 5\% de probabilidade.

\section{Resultados e discussão}

De modo geral, todos os tratamentos avaliados mostraram-se seletivos ao cultivar de soja CD-214 $\mathrm{RR}^{\circledR}$, independente da modalidade de aplicação. Assim, foram atribuídas nota 1,0 para todos os tratamentos, segundo a escala EWRC (dados não apresentados). Estudando a seletividade de 
herbicidas na cultura da soja, Morais et al. (1998) não observaram danos severos de sulfentrazone à oleaginosa.

Os cultivares comerciais de soja apresentam tolerância diferencial ao herbicida sulfentrazone (Lopez-Ovejero, 2006). Segundo Arruda et al. (1999), a toxicidade causada por este herbicida nas diversas variedades de soja está intimamente relacionada à rapidez com que o herbicida é metabolizado. El Naggar et al. (1992) relatam que, nas plantas tolerantes, ocorre rápida degradação oxidativa do produto, como forma de detoxificação, pela enzima peroxidase.

As aplicações de manejo e de préplantio apresentaram excelente controle das plantas daninhas, sendo que não houve diferença entre os tratamentos e todos apresentaram controle superior a $97 \%$.

$\mathrm{Na}$ Tabela 2, estão expostos os resultados referentes à densidade de B. pilosa. Estas, por sua vez, apresentaram comportamento variável em função da presença ou ausência da atividade residual de sulfentrazone. Verifica-se que, nos tratamentos onde foi utilizado apenas o glyphosate isolado na aplicação de manejo (T1 a T5), a densidade do picão-preto foi muito superior aos tratamentos em que se associou o sulfentrazone a $200 \mathrm{~g} \mathrm{ha}^{-1}$ (Tabela 2). Isso evidencia o bom desempenho do herbicida sulfentrazone para o controle desta espécie. Da mesma forma, podese observar a atividade residual do sulfentrazone, já que houve uma redução média de $74,80 \%$ da densidade de B. pilosa, em relação à média das respectivas testemunhas duplas (Tabela 2).

Além disso, o sulfentrazone atrasou o crescimento do picão-preto, facilitando, dessa forma, seu controle em pós-emergência. Cobucci et al. (2004) corroboram esta afirmação, pois, estudando a eficiência de herbicidas residuais para controle de plantas daninhas, verificaram que o sulfentrazone reduziu o crescimento inicial do picão-preto. Nicolai et al. (2006) também observaram a eficácia do herbicida sulfentrazone para o controle de B. pilosa.

Para Commelina benghalensis, os resultados foram similares. Nota-se na Tabela 3 que, nos tratamentos com sulfentrazone, a densidade média de plantas daninhas foi de 1,35 plantas $\mathrm{m}^{-2}$, enquanto que nas testemunhas duplas esses valores sobem para 4,15 plantas. Portanto, houve uma redução de $67,5 \%$ na infestação de $C$. benghalensis. Monquero et al. (2001) relatam que o herbicida sulfentrazone aplicado isoladamente ou em mistura com glyphosate apresenta, para Commelina benghalensis, ótimos níveis de controle e, ainda, a mistura com glyphosate apresenta interações aditivas para tal espécie.

Vários são os relatos de redução da produtividade em função da matocompetição. Para Carvalho et al. (2000) e Procópio et al. (2007), a associação de herbicidas que possuem efeito residual com herbicidas dessecantes apresenta-se como uma alternativa para reduzir as infestações de plantas daninhas, principalmente no início do desenvolvimento da cultura.

As aplicações realizadas em pósemergência em diferentes épocas com glyphosate apresentaram controles entre excelente e bom. As aplicações realizadas aos 14 e 21 DAE exerceram controle efetivo. Estes resultados são atribuídos ao estádio de desenvolvimento das plantas daninhas. Em contrapartida, as aplicações realizadas aos 28 e 35 DAE foram menos efetivas. Vale ressaltar que a presença do sulfentrazone a $200 \mathrm{~g} \mathrm{ha}^{-1}$ auxiliou a eficiência do glyphosate em pósemergência, garantindo maior supressão das plantas daninhas, fato observado principalmente aos 28 e 35 DAE. 
Tabela 1. Tratamentos, dosagens e épocas de aplicação dos tratamentos utilizados no manejo de plantas daninhas na cultura da soja $\mathrm{RR}^{\circledR}$. Bandeirantes, PR, 2006/2007.

\begin{tabular}{|c|c|c|c|c|}
\hline \multirow{2}{*}{ Tratamentos (Manejo) $^{1}$} & \multirow{2}{*}{ Dose g e.a. ou i.a. ha-1 } & \multicolumn{3}{|c|}{ Tratamentos (Pós emergência) } \\
\hline & & Herbicida & Dose & Época (DAE) \\
\hline 01. glyphosate & 1080 & glyphosate & $980 / 980$ & $14 / 28$ \\
\hline 02. glyphosate & 1080 & glyphosate & $980 / 980$ & $21 / 35$ \\
\hline 03. glyphosate & 1080 & glyphosate & 980 & 21 \\
\hline 04. glyphosate & 1080 & glyphosate & 980 & 28 \\
\hline 05. glyphosate & 1080 & glyphosate & 980 & 35 \\
\hline 06. glyphosate+sulfentrazone & $1080+200$ & glyphosate & $980 / 980$ & $14 / 28$ \\
\hline 07. glyphosate+sulfentrazone & $1080+200$ & glyphosate & $980 / 980$ & $21 / 35$ \\
\hline 08. glyphosate+sulfentrazone & $1080+200$ & glyphosate & 980 & 21 \\
\hline 09. glyphosate+sulfentrazone & $1080+200$ & glyphosate & 980 & 28 \\
\hline 10. glyphosate+sulfentrazone & $1080+200$ & glyphosate & 980 & 35 \\
\hline 11. glyphosate & 1080 & testemunha & - & - \\
\hline
\end{tabular}

${ }^{1}$ Tratamentos aplicados na operação de manejo em pré-plantio 


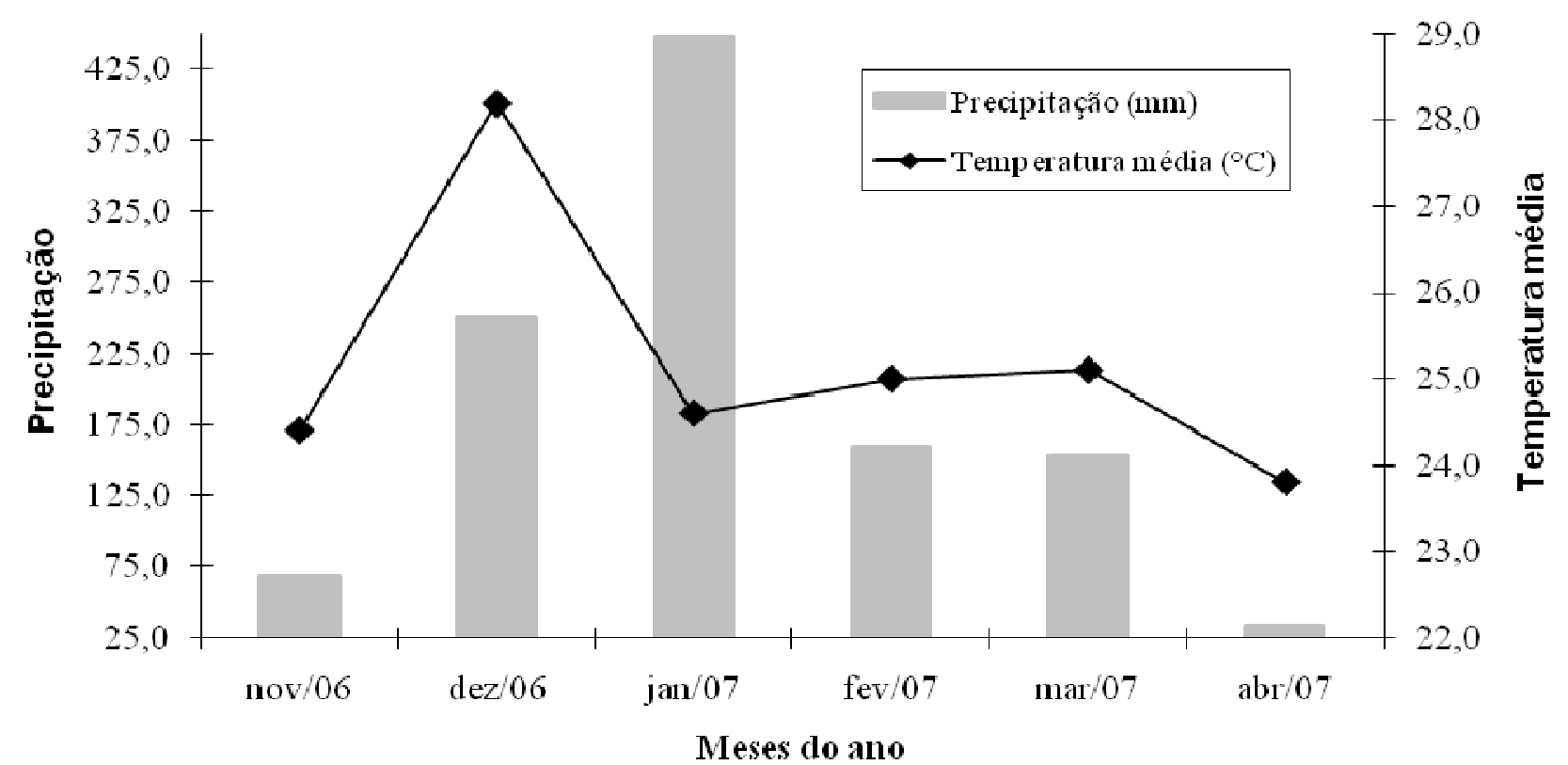

Figura 1. Precipitação pluvial $(\mathrm{mm})$ e temperatura média $\left({ }^{\circ} \mathrm{C}\right)$ no período entre novembro de 2006 e abril de 2007. Dados obtidos na estação agrometeorológica de Bandeirantes, PR. Convênio IAPAR e UENP/CLM. 
Tabela 2. Densidade de Bidens pilosa nos tratamentos e em suas respectivas testemunhas duplas, aos 24 DAE. Bandeirantes, PR, 2006/2007.

\begin{tabular}{|c|c|c|c|c|c|c|c|}
\hline \multirow{2}{*}{ Manejo } & \multirow{2}{*}{ Dose g e.a. ou i.a. ha ${ }^{-1}$} & \multicolumn{2}{|c|}{ Pós-emergência (glyphosate) } & \multicolumn{4}{|c|}{ B. pilosa $\left(\right.$ plantas $\left.\mathrm{m}^{-2}\right)$} \\
\hline & & Época (DAE) & Dose g e.a. ha ${ }^{-1}$ & Tratame & nto & Testemun & $\mathrm{ha}^{\mathrm{l}}$ \\
\hline 01. glyphosate & 1080 & $14 / 28$ & $980 / 980$ & 30,25 & $\mathrm{a}$ & 31,00 & $\mathrm{a}$ \\
\hline 02. glyphosate & 1080 & $21 / 35$ & $980 / 980$ & 39,25 & $\mathrm{a}$ & 32,00 & $\mathrm{a}$ \\
\hline 03. glyphosate & 1080 & 21 & 980 & 38,00 & $\mathrm{a}$ & 50,50 & b \\
\hline 04. glyphosate & 1080 & 28 & 980 & 30,75 & $\mathrm{a}$ & 67,50 & $\mathrm{~b}$ \\
\hline 05. glyphosate & 1080 & 35 & 980 & 35,25 & $\mathrm{a}$ & 50,75 & b \\
\hline 06. glyphosate+sulfentrazone & $1080+200$ & $14 / 28$ & $980 / 980$ & 11,50 & $\mathrm{a}$ & 36,00 & $\mathrm{~b}$ \\
\hline 07. glyphosate+sulfentrazone & $1080+200$ & $21 / 35$ & $980 / 980$ & 8,50 & $\mathrm{a}$ & 41,00 & b \\
\hline 08. glyphosate+sulfentrazone & $1080+200$ & 21 & 980 & 6,50 & $\mathrm{a}$ & 31,00 & $\mathrm{~b}$ \\
\hline 09. glyphosate+sulfentrazone & $1080+200$ & 28 & 980 & 3,00 & $\mathrm{a}$ & 18,00 & $b$ \\
\hline 10. glyphosate+sulfentrazone & $1080+200$ & 35 & 980 & 8,25 & $\mathrm{a}$ & 24,00 & $\mathrm{~b}$ \\
\hline 11. glyphosate & 1080 & - & - & 19,00 & $\mathrm{a}$ & 29,50 & $\mathrm{a}$ \\
\hline C.V. (\%) & & & & \multicolumn{4}{|c|}{31,44} \\
\hline DMS $(\mathrm{p} \leq 0,05)$ & & & & \multicolumn{4}{|c|}{11,94} \\
\hline
\end{tabular}

Médias seguidas na linha pela mesma letra não diferem entre si pelo teste de Tukey a 5\% de probabilidade.

${ }^{1}$ Testemunha adjacente ou dupla. 
Tabela 3. Densidade de Commelina benghalensis nos tratamentos e em suas respectivas testemunhas duplas, aos 24 DAE. Bandeirantes, PR, 2006/2007.

\begin{tabular}{|c|c|c|c|c|c|c|c|}
\hline \multirow{2}{*}{ Manejo } & \multirow{2}{*}{ Dose g e.a. ou i.a. ha $^{-1}$} & \multicolumn{2}{|c|}{ Pós-emergência (glyphosate) } & \multicolumn{4}{|c|}{ C. benghalensis (plantas $\mathrm{m}^{-2}$ ) } \\
\hline & & Época (DAE) & Dose g e.a. ha ${ }^{-1}$ & Tratame & ento & Testemu & nha $^{1}$ \\
\hline 01. glyphosate & 1080 & $14 / 28$ & $980 / 980$ & 2,00 & $\mathrm{a}$ & 2,00 & $\mathrm{a}$ \\
\hline 02. glyphosate & 1080 & $21 / 35$ & $980 / 980$ & 3,00 & $\mathrm{a}$ & 3,00 & $\mathrm{a}$ \\
\hline 03. glyphosate & 1080 & 21 & 980 & 3,50 & $\mathrm{a}$ & 3,75 & $\mathrm{a}$ \\
\hline 04. glyphosate & 1080 & 28 & 980 & 3,00 & $\mathrm{a}$ & 3,75 & a \\
\hline 05. glyphosate & 1080 & 35 & 980 & 3,25 & $\mathrm{a}$ & 3,50 & $\mathrm{a}$ \\
\hline 06. glyphosate+sulfentrazone & $1080+200$ & $14 / 28$ & $980 / 980$ & 0,00 & $\mathrm{a}$ & 4,00 & $\mathrm{~b}$ \\
\hline 07. glyphosate+sulfentrazone & $1080+200$ & $21 / 35$ & $980 / 980$ & 1,50 & $\mathrm{a}$ & 5,00 & $\mathrm{~b}$ \\
\hline 08. glyphosate+sulfentrazone & $1080+200$ & 21 & 980 & 1,75 & $\mathrm{a}$ & 4,75 & $\mathrm{~b}$ \\
\hline 09. glyphosate+sulfentrazone & $1080+200$ & 28 & 980 & 1,75 & $\mathrm{a}$ & 3,25 & $\mathrm{a}$ \\
\hline 10. glyphosate+sulfentrazone & $1080+200$ & 35 & 980 & 1,75 & $\mathrm{a}$ & 3,75 & a \\
\hline 11. glyphosate & 1080 & - & - & 3,50 & $\mathrm{a}$ & 4,00 & $\mathrm{a}$ \\
\hline C.V. $(\%)$ & & & & \multicolumn{4}{|c|}{61,69} \\
\hline DMS $(\mathrm{p}<0,05)$ & & & & \multicolumn{4}{|c|}{2,56} \\
\hline
\end{tabular}

Médias seguidas na linha pela mesma letra não diferem entre si pelo teste de Tukey a 5\% de probabilidade.

${ }^{1}$ Testemunha adjacente ou dupla. 
Tabela 4. Dados de produtividade $\left(\mathrm{kg} \mathrm{ha}^{-1}\right)$ dos tratamentos e de suas respectivas testemunhas duplas. Bandeirantes, PR, $2006 / 2007$.

\begin{tabular}{|c|c|c|c|c|c|c|c|}
\hline \multirow{2}{*}{ Manejo } & \multirow{2}{*}{ Dose g e.a. ou i.a. ha ${ }^{-1}$} & \multicolumn{2}{|c|}{ Pós-emergência (glyphosate) } & \multicolumn{4}{|c|}{ Produtividade $\left(\mathrm{kg} \mathrm{ha}^{-1}\right)$} \\
\hline & & Época (DAE) & Dose g e.a. ha ${ }^{-1}$ & Tratame & nto & Testemu & \\
\hline 01. glyphosate & 1080 & $14 / 28$ & 980/980 & 2027,75 & $\mathrm{a}$ & 1766,75 & $\mathrm{a}$ \\
\hline 02. glyphosate & 1080 & $21 / 35$ & $980 / 980$ & 1900,00 & a & 1742,00 & $\mathrm{a}$ \\
\hline 03. glyphosate & 1080 & 21 & 980 & 1777,75 & a & 1852,75 & $\mathrm{a}$ \\
\hline 04. glyphosate & 1080 & 28 & 980 & 1791,75 & a & 1836,25 & $\mathrm{a}$ \\
\hline 05. glyphosate & 1080 & 35 & 980 & 1672,00 & $\mathrm{a}$ & 1750,00 & $\mathrm{a}$ \\
\hline 06. glyphosate+sulfentrazone & $1080+200$ & $14 / 28$ & $980 / 980$ & 2314,00 & a & 1720,00 & $\mathrm{~b}$ \\
\hline 07. glyphosate+sulfentrazone & $1080+200$ & $21 / 35$ & 980/980 & 2277,50 & a & 1809,75 & $\mathrm{a}$ \\
\hline 08. glyphosate+sulfentrazone & $1080+200$ & 21 & 980 & 2177,75 & $\mathrm{a}$ & 1879,25 & $\mathrm{a}$ \\
\hline 09. glyphosate+sulfentrazone & $1080+200$ & 28 & 980 & 2064,00 & $\mathrm{a}$ & 1931,75 & $\mathrm{a}$ \\
\hline 10. glyphosate+sulfentrazone & $1080+200$ & 35 & 980 & 1958,25 & $\mathrm{a}$ & 1847,25 & $\mathrm{a}$ \\
\hline 11. glyphosate & 1080 & - & - & 769,50 & $\mathrm{~b}$ & 1784,75 & $\mathrm{a}$ \\
\hline C.V. $(\%)$ & & & & & & & \\
\hline DMS $(p<0,05)$ & & & & & & & \\
\hline
\end{tabular}

Médias seguidas na linha pela mesma letra não diferem entre si pelo teste de Tukey a 5\% de probabilidade.

${ }^{1}$ Testemunha adjacente ou dupla. 
$\mathrm{Na}$ Tabela 4, estão os resultados referentes à produtividade, onde é possível observar que os maiores acréscimos foram obtidos pelos tratamentos com a mistura glyphosate+sulfentrazone. No tratamento 06, o acréscimo de produtividade foi de $34,53 \%$, havendo diferença significativa em relação à sua testemunha dupla. Pode-se dizer que a presença das plantas daninhas competindo com a soja, no início de seu desenvolvimento, levou a essa redução. $\mathrm{O}$ manejo adequado das plantas daninhas proporciona a formação de maior e mais precoce área foliar da soja, com benefícios diretos na complementação do controle e, consequentemente, na produtividade da cultura (Durigan et al., 1983).

Comparando-se a produtividade entre os tratamentos nas diferentes épocas de aplicação do pós-emergente com manejo présemeadura de glyphosate+sulfentrazone contra o glyphosate isolado, constatam-se valores entre 14,10 e $22,49 \%$, superiores onde se associou o herbicida residual. Segundo Lamego et al. (2004), os efeitos decorrentes da interferência de plantas daninhas sobre características de plantas cultivadas podem comprometer o desenvolvimento de estruturas reprodutivas e afetar os componentes da produtividade de grãos. Para Silva (2009), a interferência das plantas daninhas durante o ciclo da cultura pode reduzir o rendimento de grãos de soja, com perdas de $73 \%$ até $92,5 \%$, dependendo do grau de infestação.

\section{Conclusões}

O uso do herbicida sulfentrazone, associado com o glyphosate, na pré-semeadura da cultura da soja, é uma excelente estratégia para reduzir a influência da matocompetição. Esta associação trouxe maior flexibilidade no manejo de plantas daninhas, além da garantia de seletividade à cultura.

\section{Referências}

ARRUDA, J.S.; LOPES, N.F.; BACARIN, M.A. Crescimento de plantas de soja em função de doses de sulfentrazone. Planta Daninha, v.17, n.3, p.375-386, 1999.

CARVALHO, F.T. et al. Manejo químico das plantas daninhas Euphorbia heterophylla e Bidens pilosa em sistema de plantio direto da cultura de soja. Planta Daninha, v.21, n.1, p.145-150, 2003.

CASAROLI, D. et al. Radiação solar e aspectos fisiológicos na cultura da soja. Revista da FZVA, v.14, n.2, p.102-120. 2007.

COBUCCI, T. et al. Efeito residual de herbicidas em pré-plantio do feijoeiro, em dois sistemas de aplicação em plantio direto e sua viabilidade econômica. Planta Daninha, v.22, n.4, 2004.

CONSTANTIN, J. et al. Estimativa do período que antecede a interferência de plantas daninhas na cultura da soja, Var. Coodetec 202, por meio de testemunhas duplas. Planta Daninha, v.25, n.2, p.231-237, 2007.

DAMALAS, C.A.; ELEFTHEROHORINOS, I.G. Dicamba and atrazine antagonism on sulfonylurea herbicides used for Johnsongrass (Sorghum halepense) control in corn (Zea mays). Weed Technol., v.15, n.1, p.62-67, 2001.

DURIGAN, J.C. et al. Período de matocompetição na cultura da soja (Glycine $\max$ L. Merrill), cultivares Santa Rosa e IAC 2. 1 - Efeitos sobre os parâmetros de produção. Planta Daninha, v.6, n.2, p.86-100, 1983.

EL NAGGAR, S.F. et al. Metabolism of clomazone herbicide in soybean. Food Chem., v.40, p.880-883, 1992.

FAGLIARI, J.R.; OLIVEIRA JR., R.S.; CONSTANTIN, J. Métodos de Avaliação da 
seletividade de herbicidas para a cultura da cana-de-açúcar (Saccharum spp.). Acta Sci. Agro. v.23, n.1, p.1229-1234, 2001.

JAREMTCHUK, C.C. et al. Efeito de sistemas de manejo sobre a velocidade de dessecação, infestação inicial de plantas daninhas e desenvolvimento e produtividade de soja. Acta Sci. Agro., v.30, n.4, p.449-455, 2008.

LAMEGO, F.P. et al. Tolerância a interferência de plantas competidoras e habilidade de supressão por genótipos de soja - II. Resposta de variáveis de produtividade. Planta Daninha, v.22, n.4, p.491-498, 2004.

LOPEZ-OVEJERO, R.F. et al. Alternativas de manejo químico da planta daninha Digitaria ciliaris resistente aos herbicidas inibidores da ACCase na cultura de soja. Planta Daninha, v.24, n.2, p.407-414, 2006.

MESCHEDE, D.K. et al. Período anterior á interferência de plantas daninhas em soja: estudo de caso com baixo estande e testemunhas duplas. Planta Daninha, v.22, n.2, p.239-246, 2004.

MONQUERO, P.A.; CHRISTOFFOLETI, P.J.; SANTOS, C.T.D. Glyphosate em mistura com herbicidas alternativos para o manejo de plantas daninhas. Planta Daninha, v.19, n.3, p.375-380, 2001.

MORAIS, L. Z. et al. Eficiência e seletividade de herbicidas na cultura da soja (Glycine max (L.) Merril) em área de cerrado. Pesq. Agrop. Trop., v.28, n.2, p.113-118, 1998.

NEPOMUCENO, M. et al . Períodos de interferência das plantas daninhas na cultura da soja nos sistemas de semeadura direta e convencional. Planta Daninha, v.25, n.1, p.43-50, 2007.

NICOLAI, M. et al. Alternativas de manejo para as populações de picão-preto (Bidens pilosa e Bidens subalternans) resistentes aos herbicidas inibidores da ALS. R. Bras. Herb. v.5 n.3, p.72-79, 2006.

PITELLI, R. A. Competição e controle das plantas daninhas em áreas agrícolas. Série Técnica IPEF, v.4, n.12, p. 1-24, 1987.

PITELLI, R.A. Interferência das plantas daninhas nas culturas agrícolas. Informe Agropecuário, v.11, n.129, p.16-27, 1985.

RODRIGUES, B. N.; ALMEIDA, F. S. Guia de herbicidas. 5.ed. Londrina: 2005. 591 p.

SILVA, A.F. et al. Período anterior à interferência na cultura da soja - RR em condições de baixa, média e alta infestação. Planta Daninha, v.27, n.1, p.57-66, 2009.

VANGESSEL, M.J.; AYENI, A.O.; MAJEK, B.A. Optimum glyphosate timing with or without residual herbicides in glyphosateresistant soybeans (Glycine max) under fullseason conventional tillage. Weed Technol., v.14, n.1, p.140-149, 2000. 